\title{
Effectiveness of antiretroviral therapy in treatment-naïve patients. Results at 24 and 48 weeks
}

\author{
Ana Gomez-Lobon ${ }^{1}$, Joaquin Serrano Lopez De Las Hazas ${ }^{2}$, Francisco Javier Fanjul Losa ${ }^{1}$, \\ Pilar Rovira Torres ${ }^{1}$, Ana Vanrell Ballesteros ${ }^{2}$, Antonio Payeras Cifre ${ }^{2}$, Melchor Riera Jaume
}

${ }^{1}$ Hospital Universitario Son Espases, Palma de Mallorca, Spain

${ }^{2}$ Hospital Son Llàtzer, Palma de Mallorca, Spain

\begin{abstract}
Introduction: Since 2015, integrase strand transfer inhibitors (INSTI)-based regimens have been considered as the preferred option for antiretroviral therapy (ART)-naive patients. The main objective of this study was to identify the ART-regimens selected for treatment-naive patients during 2015 in two tertiary hospitals, determine the rate of virological failure at 24 and 48 weeks, and compare the results with those of previous years (2012-2014).

Material and methods: Four-year retrospective study. Adult ART-naïve patients who had started treatment between 2012 and 2015 were selected. Clinical data, laboratory tests performed, and ART selected were recorded.

Results: A total of 536 patients were included, 137 from 2015 and 399 from 2012-2014. The most common ART regimens prescribed in 2015, compared to 2012-2014, were INSTI-based regimens (68.6\% vs. $4.8 \%)$, followed by non-nucleoside reverse transcriptase inhibitor (NNRTI)-based regimens (20.4\% vs. $52.8 \%)$ and PI-based regimens (10.9\% vs. $42.5 \%)$. Most patients received a singletablet regimen $(78.8 \%$ vs. $51.9 \%)$. In $2015,72.3 \%$ of patients had a viral load (VL) $<50$ copies $/ \mathrm{ml}$ at week 24 and $83.9 \%$ at week 48 , compared to $55.1 \%$ and $74.7 \%$, respectively, in $2012-2014$. During the 48 -week follow-up, the ART regimen was changed in $22.6 \%$ of patients in 2015 and $29.3 \%$ in 2012 2014. The main reason was simplification ( $45.2 \%$ vs. $22.2 \%$ ) followed by side effects ( $25.8 \%$ vs. $38.5 \%)$.

Conclusions: In 2015, INSTI-based regimens were prescribed in nearly $70 \%$ of ART-naïve patients. This change in trend in the starting ART regimen results in a greater number of patients achieving a VL $<50$ copies/ml at weeks 24 and 48 and in a reduction in ART changes due to adverse effects.
\end{abstract}

HIV AIDS Rev 2019; 18, 2: 100-106 DOI: https://doi.org/10.5114/hivar.2019.86374

Key words: adult, anti-HIV agents, HIV infections, treatment outcome, viral load.

\section{Introduction}

Most scientific associations currently recommend starting antiretroviral therapy (ART) in all human immunodeficiency virus (HIV)-infected patients [1-3] because evidence sug- gests that delaying ART initiation is associated with greater mortality and serious acquired immunodeficiency syndrome (AIDS)- or non-AIDS-related complications $[4,5]$.

With the combinations of ARTs available these past few years, the target viral load (VL) of $<50$ copies $/ \mathrm{ml}$ was
Address for correspondence: Ana Gomez-Lobon,

Hospital Universitario Son Espases, Crta. Valldemossa, 79.,

07120, Palma de Mallorca, Spain, phone: +34600304107 ,

e-mail: ana.gomez@ssib.es
Article history:

Received: 25.06.2018

Received in revised form: 31.08 .2018

Accepted: 20.05.2019

Available online: 16.06.2019
International Journal of HIV-Related Problems

HIV \& AIDS R e v i e w 
achieved in more than $75 \%$ of cases at 48 weeks $[1,6,7]$ The number of preferred combinations for ART-naïve patients has been progressively reduced since 2015, especially in the Spanish GESIDA guidelines, which were the first ones to give integrase strand transfer inhibitors (INSTI) precedence over other drug families [1].

The success of strategies in achieving sustained virological suppression depends on the appropriate selection of the starting regimen, the performance of a prior drug resistance mutation (DRM) test, and good adherence. Other factors that are considered as predictors of success are low pre-therapy baseline viraemia and baseline CD 4 count above 200 cells $/ \mu \mathrm{l}$ $[1,2,6-8]$.

Although one of the treatment goals described in all the guidelines is the achievement of prolonged suppression, there are discrepancies regarding the concept of virological failure (VF). While most guidelines [1, 3, 9] concur in their definition of VF as two consecutive measurements of $\mathrm{VL}>50$ copies/ml at 24 weeks following ART initiation, the DHHS [2] defines it as the inability to achieve or maintain viral replication below 200 copies/ml. VF is also considered if, following the achievement of virological suppression at week 24, VL becomes detectable again in two consecutive measurements.

Furthermore, increased importance has been given over the last few years to the CD4/CD8 ratio in patients with HIV infection. In these patients, an inversion of this ratio to levels below 1 is considered as a surrogate marker of immunosenescence, available in standard clinical practice, and has shown to be an independent predictor of mortality in the elderly [10].

The primary objective of this study was to determine the type of ART selected as starting therapy for naive patients throughout 2015 in a real-life situation in two tertiary hospitals, the rate of VF at 24 and 48 weeks, and whether results differed from 2012-2014.

The secondary objectives were to analyse changes in ART and reasons for change, variations in the CD4/CD8 ratio, and the relationship between the different predictors of success described and the results obtained.

\section{Material and methods}

A four-year retrospective study at two tertiary hospitals was conducted. Adult naive HIV-infected patients who had initiated ART between January 2012 and December 2015 were selected. Patients having started treatment because of pregnancy were excluded.

The follow-up period was 48 weeks. The data collected were demographics, and clinical and laboratory data (VL, CD4 counts, CD4/CD8 ratio) both at baseline and at weeks 24 and 48 of treatment, with a window of up to four weeks, and ART chosen. Follow-up and adherence data were also collected.

Changes in ART during the first year and reason for change were recorded.
Virological success or treatment failure was determined at 24 and 48 weeks using two types of analyses in which VF was defined as VL $>50$ copies $/ \mathrm{ml} 24$ and 48 weeks following ART initiation, as VL that did not become undetectable at any time, or when, following virological suppression, it became detectable again in two consecutive measurements (definition of the GESIDA, EACS, and IAS guidelines) or as the inability to achieve or sustain viral replication below 200 copies/ml (DHHS guidelines).

Good follow-up was considered when patients came to more than $80 \%$ of the medical appointments scheduled for that year, and adherence was considered adequate when it was greater than $90 \%$. Adherence records are registered in the eVIAh database based on the pharmacies' dispensation logs.

Data were analysed on an intent-to-treat and per protocol basis. Continuous variables are presented as mean (standard deviation) or median (interquartile range) depending on their distribution, and categorical variables are presented as percentages.

A univariate statistical analysis was performed comparing differences between groups using $\chi^{2}$, Student's $t$, ANOVA, and Mann-Whitney $U$ tests based on their distribution and the number of groups being compared. The multivariate analysis was conducted using a logistic regression to calculate the odds ratios (OR) of the statistically significant variables in the univariate analysis and variables associated to risk of virological failure in the literature. They were considered significant when $p<0.05$.

All the data were obtained from the eVIAh database, which is a database used by both sites for the follow-up of HIV patients at the Outpatient Clinics, and they were collated with electronic medical records when necessary. Patients had signed a prior informed consent for the "Multicentre Cohort of HIV-infected adults (PISCIS)" or "CoRIS" authorising their data to be entered in this database.

Data were anonymised, and the IBM SPSS Statistics v.22 software was used for the statistical analysis.

This study was authorised by the Research Ethics Committee (REC) of the Balearic Islands, Spain (code EST-TAR2016-01).

\section{Results}

A total of 536 patients having initiated ART were enrolled, 399 in the 2012-2014 period and 137 in 2015. Sociodemographic, clinical, laboratory, and treatment data are provided in Table 1. The most important differences between both periods were related to age at therapy initiation, CD4 counts, and type of ART selected. The most common combinations in 2012-2014 were the ones that included a non-nucleoside reverse transcriptase inhibitor (NNRTI) or a protease inhibitor (PI), with efavirenz (30.1\%), dolutegravir $(27.1 \%)$, and rilpivirine $(21.6 \%)$ as the most commonly used drugs. In 2015, INSTIs represented the main family of drugs used, with dolutegravir (46\%), elvitegravir/cobici- 
Table 1. Demographic, clinical, and treatment data

\begin{tabular}{|c|c|c|c|c|c|}
\hline Factor & 2012-2014 & $\%$ & 2015 & $\%$ & $p$ \\
\hline $\mathrm{N}^{\circ}$ of patients & 399 & - & 137 & - & \\
\hline Mean age & $42.1 \pm 9.9$ & Min: 22, Max: 80 & $39.1 \pm 9.5$ & Min: 21, Max: 71 & 0.001 \\
\hline \multicolumn{6}{|l|}{ Gender } \\
\hline Male & 345 & 86.5 & 114 & 83.2 & 0.349 \\
\hline \multicolumn{6}{|l|}{ Nationality } \\
\hline Spanish & 160 & 40.1 & 69 & 50.4 & \multirow[t]{3}{*}{0.005} \\
\hline Foreigner & 90 & 22.6 & 17 & 12.4 & \\
\hline Not recorded & 149 & 37.3 & 51 & 37.2 & \\
\hline \multicolumn{6}{|l|}{ HCV co-infection } \\
\hline Yes & 68 & 17 & 11 & 8 & 0.034 \\
\hline \multicolumn{6}{|l|}{ Transmission mechanism } \\
\hline Homosexual & 194 & 48.6 & 67 & 48.9 & \multirow[t]{3}{*}{0.088} \\
\hline Heterosexual & 138 & 34.6 & 55 & 40.1 & \\
\hline IDU & 49 & 12.3 & 6 & 4.4 & \\
\hline \multicolumn{6}{|l|}{ CD4 range } \\
\hline$<200$ & 124 & 31.1 & 31 & 22.6 & \multirow[t]{4}{*}{$<0.001$} \\
\hline $200-350$ & 112 & 28.1 & 37 & 27 & \\
\hline $350-500$ & 128 & 32.1 & 36 & 26.3 & \\
\hline$>500$ & 35 & 8.8 & 33 & 24.1 & \\
\hline Mean VL log & $4.7 \pm 0.8$ & & $4.7 \pm 0.8$ & & 0.716 \\
\hline \multicolumn{6}{|l|}{ High baseline VL } \\
\hline$V L>100,000$ & 146 & 36.6 & 50 & 36.5 & 0.983 \\
\hline \multicolumn{6}{|l|}{ Prior resistance study } \\
\hline Performed & 281 & 70.4 & 112 & 81.8 & 0.010 \\
\hline \multicolumn{6}{|l|}{ Selected ART } \\
\hline $2 N R T I+1 N N R T I$ & 210 & 52.8 & 28 & 20.4 & \multirow[t]{3}{*}{$<0.001$} \\
\hline $2 \mathrm{NRTI}+1 \mathrm{PI}$ & 169 & 42.5 & 15 & 10.9 & \\
\hline $2 N R T I+1 I N S T I$ & 19 & 4.8 & 94 & 68.6 & \\
\hline \multicolumn{6}{|l|}{ Single daily dose } \\
\hline Yes & 207 & 51.9 & 108 & 78.8 & $<0.001$ \\
\hline Discontinuation of starting ART & 117 & 29.3 & 31 & 22.6 & 0.130 \\
\hline Start of second ART & 92 & 23.1 & 25 & 18.2 & 0.240 \\
\hline \multicolumn{6}{|l|}{$2^{\text {nd }} A R T$ selected } \\
\hline $2 \mathrm{NRTI}+1 \mathrm{NNRTI}$ & 39 & 42.4 & 2 & 8 & \multirow[t]{4}{*}{$<0.001$} \\
\hline $2 \mathrm{NRTI}+1 \mathrm{PI}$ & 32 & 34.8 & 5 & 20 & \\
\hline $2 \mathrm{NRTI}+1$ INSTI & 20 & 21.7 & 18 & 72 & \\
\hline $1 \mathrm{PI}+1 \mathrm{INSTI}$ & 1 & 1.1 & 0 & 0 & \\
\hline \multicolumn{6}{|l|}{ Single daily dose $2^{\text {nd }} A R T$} \\
\hline No & 50 & 54.3 & 6 & 24 & \multirow[t]{2}{*}{0.007} \\
\hline Yes & 42 & 45.7 & 19 & 76 & \\
\hline \multicolumn{6}{|l|}{ Follow-up visits } \\
\hline$>80 \%$ & 336 & 84.2 & 119 & 86.9 & \multirow[t]{2}{*}{0.484} \\
\hline$<80 \%$ & 59 & 14.8 & 17 & 12.4 & \\
\hline \multicolumn{6}{|l|}{ ART adherence } \\
\hline$>90 \%$ & 169 & 42.4 & 74 & 54 & \multirow[t]{2}{*}{0.756} \\
\hline$<90 \%$ & 16 & 4 & 6 & 4.4 & \\
\hline
\end{tabular}


Table 2. Viral load results at 24 and 48 weeks

\begin{tabular}{|c|c|c|c|c|c|c|c|}
\hline Results & $\begin{array}{c}2012-2014 \\
\text { (n) }\end{array}$ & $\begin{array}{l}\text { Absolute } \\
\text { (\%) }\end{array}$ & $\begin{array}{l}\text { Relative } \\
\text { (\%) }\end{array}$ & $\begin{array}{c}2015 \\
(n)\end{array}$ & $\begin{array}{l}\text { Absolute } \\
\text { (\%) }\end{array}$ & $\begin{array}{c}\text { Relative } \\
\text { (\%) }\end{array}$ & $p$ \\
\hline \multicolumn{8}{|l|}{ Results at 24 weeks } \\
\hline Patients with VL data & 379 & 95.0 & 100.0 & 126 & 92.0 & 100.0 & \\
\hline $\mathrm{VL}<200$ copies $/ \mathrm{ml}$ & 307 & 76.9 & 81.0 & 121 & 88.3 & 96.0 & $<0.001$ \\
\hline $\mathrm{VL}<50$ copies $/ \mathrm{ml}$ & 220 & 55.1 & 58.0 & 99 & 72.3 & 78.6 & $<0.001$ \\
\hline \multicolumn{8}{|l|}{ Results at 48 weeks } \\
\hline Patients with VL data & 349 & 87.5 & 100.0 & 124 & 90.5 & 100.0 & \\
\hline $\mathrm{VL}<200$ copies $/ \mathrm{ml}$ & 337 & 84.5 & 96.6 & 122 & 89.1 & 98.4 & 0.374 \\
\hline $\mathrm{VL}<50$ copies $/ \mathrm{ml}$ & 298 & 74.7 & 85.4 & 115 & 83.9 & 92.7 & 0.040 \\
\hline
\end{tabular}

$V L-$ viral load

Table 3. CD4 values (cells/mm³) and CD4/CD8 ratio

\begin{tabular}{|c|c|c|c|c|c|c|c|}
\hline \multirow{2}{*}{ CD4 distribution } & \multicolumn{3}{|c|}{ 2012-2014 } & \multicolumn{3}{|c|}{2015} & \multirow[t]{2}{*}{$p$} \\
\hline & $n$ & Median & IQR & $n$ & Median & IQR & \\
\hline Prior to ART initiation & 399 & 310.0 & $153-405$ & 137 & 353.0 & $226.5-500$ & 0.048 \\
\hline Week 48 & 353 & 478.0 & $309-631$ & 124 & 560.5 & $382-818.3$ & 0.063 \\
\hline \multicolumn{8}{|c|}{ Inter-subject variation in CD4 count } \\
\hline Week 48 & 353 & 178.0 & $82-292$ & 124 & 213.0 & $100.75-326.25$ & 0.023 \\
\hline \multicolumn{8}{|l|}{ CD4/CD8 ratio } \\
\hline Prior to ART initiation & 204 & 0.32 & $0.2-0.48$ & 86 & 0.40 & $0.227-0.57$ & 0.190 \\
\hline Week 48 & 121 & 0.48 & $0.29-0.74$ & 77 & 0.66 & $0.38-0.92$ & 0.116 \\
\hline \multicolumn{8}{|c|}{ Inter-subject variation in CD4/CD8 ratio } \\
\hline Week 48 & 102 & 0.19 & $0.07-0.30$ & 71 & 0.29 & $0.14-0.48$ & 0.154 \\
\hline
\end{tabular}

stat (21.9\%), and rilpivirine (18.2\%) as the drugs most commonly used in the starting ART.

With regard to ART effectiveness, laboratory data from $505(94.2 \%)$ patients at 24 weeks and from 473 (88.2\%) patients at 48 weeks were analysed to determine success or VF. The results in Table 2 are provided as absolute and relative values. The difference between the first and the second study period in the number of patients with a $\mathrm{VL}<50$ copies $/ \mathrm{ml}$ at 24 weeks (58.0\% vs. $78.6 \%$ ) and 48 weeks ( $85.4 \%$ vs. $91.7 \%)$ is worthy of attention.

Data on CD4 counts, CD4/CD8 ratio, and inter-subject variations between therapy initiation and week 48 are provided in Table 3 . The CD4/CD8 ratio was only recorded in one of the hospitals and not for every patient. The increase in inter-subject CD4 variation ( 178.0 vs. $213.0 ; p=0.023)$ and in the CD4/CD8 ratio ( 0.19 vs. $0.29 ; p=0.023)$ between both study periods is of note even though it did not reach statistical significance.

There were no laboratory data available at week 48 in 63 patients because no laboratory test or follow-up visit had taken place within the specified period in 39 cases, 16 patients had changed their place of residence, 15 were lost-tofollow-up, two had died, and one had withdrawn. Treatment failure occurred in 13 patients with a VL > 200 copies $/ \mathrm{ml}$ as a result of treatment discontinuation in six cases, poor adherence in five cases, lost-to-follow-up in one case, and unknown cause in one case.

Regarding changes in therapy, $27.6 \%$ of patients changed their initial ART during the first year. The primary reason in 2015 was to simplify therapy in $14(45.2 \%)$ patients, followed by side effects in eight $(25.8 \%)$ patients, and six (19.3\%) patients were lost-to-follow-up. One change was due to treatment failure, one to medical judgement, and one to pregnancy. By contrast, in 2012-2014, side effects were the primary reason for ART change in $45(38.5 \%)$ patients, followed by simplification in $26(22.2 \%)$ patients, and lost-to-follow-up in 23 (19.6\%). There were nine discontinuations based on medical judgement, four were due to drug-drug interactions, three to patient withdrawal, three to resistance study results, two to treatment failure, one to low plasma levels, and one to death.

The types of adverse effects recorded in 2012-2014 were: CNS-related (16 patients), gastrointestinal (5), dermatological (5), renal (5), hyperbilirubinaemia/jaundice (5), bone (2), metabolic (2), malaise (2), unknown (2), and neutropaenia (1). In 2015, these were gastrointestinal (3), renal (2), dermatological (1), bone (1), and unknown (1). 
Table 4. Univariate analysis of virological failure at 48 weeks of therapy

\begin{tabular}{|c|c|c|c|c|c|c|c|c|c|c|c|}
\hline & $N$ & $\mathrm{VL}<200$ & $\%$ & $V L>200$ & $\%$ & $p$ & $V L<50$ & $\%$ & $\mathrm{VL}>50$ & $\%$ & $p$ \\
\hline \multicolumn{12}{|l|}{ High baseline VL } \\
\hline$V L<100,000$ & 293 & 289 & 98.6 & 4 & 1.4 & \multirow[t]{2}{*}{0.017} & 278 & 94.9 & 15 & 5.1 & \multirow[t]{2}{*}{$<0.001$} \\
\hline $\mathrm{VL}>100,000$ & 176 & 167 & 94.9 & 9 & 5.1 & & 132 & 75.0 & 44 & 25.0 & \\
\hline \multicolumn{12}{|l|}{ Baseline CD4 count } \\
\hline$<200$ & 137 & 132 & 96.4 & 5 & 3.6 & \multirow[t]{2}{*}{0.572} & 108 & 78.8 & 29 & 21.2 & \multirow[t]{2}{*}{$<0.001$} \\
\hline$>200$ & 336 & 327 & 97.3 & 9 & 2.7 & & 305 & 90.8 & 31 & 9.2 & \\
\hline \multicolumn{12}{|l|}{ Prior RM study } \\
\hline Performed & 351 & 341 & 97.2 & 10 & 2.8 & \multirow[t]{2}{*}{0.809} & 305 & 86.9 & 46 & 13.1 & \multirow[t]{2}{*}{0.641} \\
\hline Not performed & 122 & 118 & 96.7 & 4 & 3.3 & & 108 & 88.5 & 14 & 11.5 & \\
\hline \multicolumn{12}{|l|}{ ART type } \\
\hline 2NRTI + 1NNRTI & 212 & 207 & 97.6 & 5 & 2.4 & \multirow[t]{3}{*}{0.45} & 196 & 92.5 & 16 & 7.5 & \multirow[t]{3}{*}{$<0.001$} \\
\hline $2 \mathrm{NRTI}+1 \mathrm{PI}$ & 162 & 155 & 95.7 & 7 & 4.3 & & 128 & 79.0 & 34 & 21.0 & \\
\hline $2 \mathrm{NRTI}+1 \mathrm{INSTI}$ & 98 & 96 & 98.0 & 2 & 2.0 & & 88 & 89.8 & 10 & 10.2 & \\
\hline \multicolumn{12}{|l|}{ Single daily dose } \\
\hline Yes & 281 & 276 & 98.2 & 5 & 1.8 & \multirow[t]{2}{*}{0.067} & 262 & 93.2 & 19 & 6.8 & \multirow[t]{2}{*}{$<0.001$} \\
\hline No & 192 & 183 & 95.3 & 9 & 4.7 & & 151 & 78.6 & 41 & 21.4 & \\
\hline \multicolumn{12}{|l|}{ Adherence } \\
\hline$>90 \%$ & 229 & 229 & 100.0 & 0 & 0.0 & \multirow[t]{2}{*}{$<0.001$} & 209 & 91.3 & 20 & 8.7 & \multirow[t]{2}{*}{$<0.001$} \\
\hline$<90 \%$ & 19 & 13 & 68.4 & 6 & 31.6 & & 11 & 57.9 & 8 & 42.1 & \\
\hline \multicolumn{12}{|l|}{ Follow-up } \\
\hline$>80 \%$ & 416 & 406 & 97.6 & 10 & 2.4 & \multirow[t]{2}{*}{0.054} & 366 & 88.0 & 50 & 12.0 & \multirow[t]{2}{*}{0.24} \\
\hline$<80 \%$ & 57 & 53 & 93.0 & 4 & 7.0 & & 47 & 82.5 & 10 & 17.5 & \\
\hline
\end{tabular}

ART - antiretroviral therapy, INSTI - integrase strand transfer inhibitor, NNRTI - non-nucleoside reverse transcriptase inhibitor, NRTI - nucleoside reverse transcriptase inhibitor, $\mathrm{PI}$ - protease inhibitor, $R M$ - resistance mutation, VL - viral load

Of the patients who initiated a second ART, 24 had their therapy discontinued again in 2012-2014 (six for simplification, four due to lost-to-follow-up, three to side effects, three to medical judgement, three to treatment failure, two withdrawal, two change in place of residence, and one to resistance study results), and two in 2015 (one for simplification and one due to side effects).

In the univariate analysis, if we consider VF as the inability to achieve a $\mathrm{VL}<200$ copies/ml at week 48 , the only variables associated with VF are high baseline VL and poor adherence. If we consider $\mathrm{VF}$ as the failure to achieve a $\mathrm{VL}<50$ copies $/ \mathrm{ml}$ at week 48 , then, in addition to high baseline VL and poor adherence, the baseline CD4 count and the type of starting ART become relevant, and the best results are obtained with INSTIs and NNRTIs and single-tablet regimens (STRs) (Table 4).

In the multivariate analysis, high baseline VL, baseline CD4 count below 200 copies/ml, and ART type were associated with the probability of having a $\mathrm{VL}<50$ copies $/ \mathrm{ml}$ at week 48 . Adherence was excluded from the analysis because, despite having shown statistically important differences in previous analyses, it had only been recorded in 246 patients.

A total of 468 patients were included in the analysis performed with the variables mentioned. A baseline $\mathrm{VL}<100,000$ copies/ml was associated with a higher probability of treat- ment success $(\mathrm{OR}=5.373 ; \mathrm{CI}=2.783-10.376 ; p>0.001)$. There was a significant difference in the VL $<50$ copies $/ \mathrm{ml}$ results at week 48 according to the type of ART, with PIs being the only drugs showing differences (lower effectiveness) compared to the other drug families $(\mathrm{OR}=0.425$; $\mathrm{CI}=0.192$ $0.942 ; p=0.035)$.

\section{Discussion}

The demographic and clinical data obtained in our cohort of treatment-naïve HIV-infected patients are in line with the most recent report on new HIV diagnoses published by the Spanish Ministry of Health in 2016 [11].

The number of patients initiating ART each year remained stable, mean age at therapy initiation decreased nearing mean age at diagnosis (36 years), and transmission between MSM was clearly predominant while transmission between HTSX and IDUs decreased. The number of foreigners and the percentage of patients initiating ART with advanced disease $\left(<200 \mathrm{CD} 4 / \mathrm{mm}^{3}\right)$ also decreased significantly, although late diagnosis remained at about $50 \%$, which was similar to the national mean value.

Regarding the type of ART selected as starting regimen, a significant change in drug prescription was seen in favour 
of INSTIs, as recommended by the main scientific guidelines $[1,2]$. Therapies were also simplified, with STRs representing almost $80 \%$ of starting ARTs.

With the change of trend in antiretroviral regimens, greater rates of patients with undetectable VL were achieved, with significant differences at week 24 in the number of patients with a VL $<50$ copies $/ \mathrm{ml}$ and $\mathrm{VL}<200$ copies $/ \mathrm{ml}$. At week 48 , the rate of patients with a VL $<200$ copies $/ \mathrm{ml}$ was similar for both study periods, but the number of patients with a VL $<50$ copies/ml remained higher in 2015 (92.7\% vs. $85.4 \% ; p=0.04$ ).

Studies published prior to 2015 (when recommendations in the guidelines changed in favour of INSTIs) found that between 5\% [12] and 13\% [13] of patients were changing their starting ART because of treatment failure. However, it is important to take into account that the definition of VF used in each study and the year the study was conducted or the HIV PCR technique used were not always clearly specified. In the study by Jarrin et al. [13], the authors only provide treatment failure/resistance data without clearly specifying what they considered as failure, and in the study by Keita et al. [12] treatment failure was defined not only as the inability to achieve an undetectable VL or as VL rebound but also as the onset of clinical symptoms of disease progression or the lack of increase in CD4 counts despite ART. Furthermore, other studies defined VF as "two consecutive viral loads at least 500 copies/ml or one viral load at least 500 copies $/ \mathrm{ml}$, followed by a modification of ART" [14], as "an HIV RNA viral load of $>1000$ copies/ml"[15], or as "a VL > 400 copies/ml" [16].

It is also important to note that in clinical practice it is difficult to obtain laboratory data with the same frequency at which it is generally obtained in clinical trials, so that, with the definition of therapeutic success as a VL $<50$ copies $/ \mathrm{ml}$ at 24 weeks, until 2014 this was obtained in a little over $50 \%$ of patients. As of 2015, thanks to the rapid decrease in VL achieved by INSTIs, therapeutic success increased to $72 \%$ in absolute terms at 24 weeks and was greater than $80 \%$ at 48 weeks, which is the value recommended by the current scientific guidelines [17].

Furthermore, although the global rate of treatment modifications did not decrease significantly, the number of total ART changes resulting from side effects did decrease from $11.2 \%$ of patients (38.5\% of the changes) in 2012-2014 to $5.8 \%$ ( $25.8 \%$ of the changes) in 2015 . The primary cause for changing ART in 2015 was treatment simplification, which occurred in $10.2 \%$ of patients ( $45.2 \%$ of total changes) and was due to the fact that for most of these patients, a starting combination of 2 NNRTI + INSTI in a single tablet had not been available when they had initiated therapy.

Until recently, the primary reasons for changing ARTs were toxicity followed by simplification, as shown in publications such as the CoRIS cohort [13], from 2008 to 2010, in which the most common reason for ART modification was shown to be toxicity (40\%), followed by simplification (14\%) and treatment failure/resistance (13\%).
The survey by Pedrol et al. [18] performed in Spain in 349 HIV patients in 19 hospitals to characterise the reasons for changing ARTs also found that the most common reason for change was simplification (37\%), followed by toxicity $(30 \%)$ and therapeutic failure (21\%). In another Spanish study [19] with 603 treatment-naïve patients initiating ART, the median time during which they remained with the same ART was 17.5 months. The ART had been discontinued in $36 \%$ of patients during the first year of follow-up, with toxicity as the primary cause for switching therapy (25\%), followed by simplification (19\%) and VF (15\%).

Our study shows that the current drug combinations recommended as starting regimens are better tolerated than those existing previously, and this has led to a decrease in the number of treatment discontinuations caused by side effects.

With regard to patient immunological recovery, despite the fact that in 2015 the mean CD4 count with which patients initiated therapy was higher than in previous years, a greater inter-subject increase at week 48 was observed that year. This was also associated with a greater recovery of the CD4/CD8 ratio, although it was not statistically significant, probably as a result of the low number of patients with this information. CD4/CD8 ratio normalisation in patients receiving ART is important because patients with CD4/ CD8 values $>1$ have been shown to present a T-cell phenotype very similar to that of subjects without HIV infection. Conversely, patients with a persistently low CD4/CD8 ratio $(<0.4-0.5)$ show a marked immunosenescence and a greater activation of innate immunity [10].

Finally, the global univariate analysis of factors related to treatment success or failure shows that typical factors such as baseline VL, CD4 counts above 200 cells $/ \mathrm{mm}^{3}$, type of ART selected, adequate treatment adherence, and monitoring are important for the initial ART to be successful $[6,7,17,20]$. Nevertheless, it should be noted that these factors are also influenced by the type of patient to whom a particular regimen is to be prescribed. PIs, for example, are well known to be preferably prescribed to patients with low CD4 counts, high VLs, prior DRM, or poor adherence [1], and in addition, they are not available as STRs.

By jointly analysing the influence of a high VL, the type of ART used, and baseline CD4 counts in a multivariate analysis, our study shows that only the first two factors show significant differences in the achievement of therapeutic success. Although adherence was excluded given the lack of data, it was significant in all previous analyses.

The main limitation in this study is that, because of it is a retrospective study, it lacks records of adverse reactions that did not lead to treatment modification but that could have had an impact on patient quality of life or adherence.

Another limitation is that adherence records were not complete in all patients, and a fairly high number of patients did not have records of their pre- and post-treatment CD4/ $\mathrm{CD} 8$ ratio, given that recording of this information during patients' visits started only in the past few years and, even then, not fully in most cases. 


\section{Conclusions}

In conclusion, of the patients who initiated an ART in 2015 at both hospitals under study, $72 \%$ had a VL $<50$ copies $/ \mathrm{ml}$ at 24 weeks and $84 \%$ at 48 weeks, compared to $55 \%$ and $75 \%$, respectively, for the period 2012-2014. This improvement coincides with a change in trend in the selection of the starting ART, with INSTIs as the drug family most commonly selected for the treatment of naive patients.

Approximately $25 \%$ of patients modified their starting ART in the first year of treatment. In 2015, the main reason for change was ART simplification, while in 2012-2014 the main reason for change was side effects.

Patient immunological recovery was greater in 2015. This could be influenced by both the type of antiretroviral regimen and an earlier initiation of ART.

In the analyses performed, a $\mathrm{VL}<100,000$ copies $/ \mathrm{ml}$ and the type of ART continue to be predictors of treatment success. CD 4 counts $>200$ cells $/ \mathrm{mm}^{3}$, STR combinations, and good adherence can also play an important role in treatment outcome.

This study has enabled us to determine the rate of VF in a real-life situation in two of the main hospitals of our autonomous region and to show how treatment outcome has improved as a consequence of the inclusion of INSTIs in the current therapeutic armamentarium.

\section{Acknowledgements}

We acknowledge the collaboration of Antonio Vanrell in data collection, and Claire M. Graham Besson and Graham Specialized Translations for their assistance in the translation of the manuscript.

\section{Conflict of interest}

The authors declare no potential conflicts of interest with respect to the research, authorship, and/or publication of this article.

\section{References}

1. Documento de consenso de GeSIDA/Plan Nacional sobre el Sida respecto al tratamiento antirretroviral en adultos con infección por el virus de la inmunodeficiencia humana, 2016. Available at: http://www.gesida-seimc.org/contenidos/guiasclinicas/2016/gesida-guiasclinicas-2016-tar.pdf (Accessed: 06.12.2016).

2. Guidelines for the use of antiretroviral agents in HIV-1-infected adults and adolescents. Department of Health and Human Services, 2016. Available at: https://aidsinfo.nih.gov/contentfiles/lvguidelines/ adultandadolescentgl.pdf (Accessed: 06.12.2016).

3. European Guidelines for treatment of HIV-infected adults in Europe, 2015. Available at: http://www.eacsociety.org/files/2015_eacsguidelines_8.0-english_rev-20151221.pdf (Accessed: 06.12.2016).

4. INSIGHT START Study Group, Lundgren JD, Babiker AG, Gordin F, et al. Initiation of Antiretroviral Therapy in Early Asymptomatic HIV Infection. N Engl J Med 2015; 373: 795-807.

5. TEMPRANO ANRS 12136 Study Group, Danel C, Moh R, Gabillard D, et al. A Trial of Early Antiretrovirals and Isoniazid Preventive Therapy in Africa. N Engl J Med 2015; 373: 808-822.
6. Cescon AM, Cooper C, Chan K, et al. Factors associated with virological suppression among HIV-positive individuals on highly active antiretroviral therapy in a multi-site Canadian cohort. HIV Med 2011; 12: 352-360.

7. Street E, Curtis H, Sabin CA, et al., British HIV Association (BHIVA) and BHIVA Audit and Standards Subcommittee. British HIV Association (BHIVA) national cohort outcomes audit of patients commencing antiretrovirals from naive. HIV Med 2009; 10: 337-342.

8. Suarez-Garcia I, Sobrino-Vegas P, Tejada A, et al. Compliance with national guidelines for HIV treatment and its association with mortality and treatment outcome: a study in a Spanish cohort. HIV Med 2014; 15: 86-97.

9. Consolidated guidelines on the use of antiretroviral drugs for treating and preventing HIV infection Recommendations for a public health approach - Second edition. World Health Organization, 2016. Available at: file://C:/Users/BEEP/Downloads/9789241549684_eng. pdf (Accessed: 06.12.2016).

10. Grupo de expertos del Plan Nacional sobre el sida y de la Sociedad Española de Geriatría y Gerontología. Documento de Consenso sobre edad avanzada e Infección por el virus de la inmunodeficiencia humana, 2015. Available at: http://www.msssi.gob.es/ciudadanos/enfLesiones/enfTransmisibles/sida/publicaciones/profSanitarios/docEdadAvanzadaVIH.pdf (Accessed: 06.20.2016).

11. Área de Vigilancia de VIH y Comportamientos de Riesgo. Vigilancia Epidemiológica del VIH y sida en España: Sistema de Información sobre Nuevos Diagnósticos de VIH y Registro Nacional de Casos de Sida. Plan Nacional sobre el Sida - S.G. de Promoción de la Salud y Epidemiología / Centro Nacional de Epidemiología ISCIII. Madrid, November 2016. Available at: https://www.msssi. gob.es/ciudadanos/enfLesiones/enfTransmisibles/sida/vigilancia/ InformeVIH_SIDA_2016.pdf (Accessed: 08.17.2017).

12 Keita M, Perbost I, Pugliese-Wehrlen S, et al. Incidences and risk factors of first-line HAART discontinuation: a limitation to the success of the "seek, test, treat, and retain" strategy? AIDS Care 2014; 26: 1058-1069.

13. Jarrin I, Hernandez-Novoa B, Alejos B, et al. Persistence of novel first-line antiretroviral regimes in a cohort of HIV-positive subjects, CoRIS 2008-2010. Antivir Ther 2013; 18: 161-170.

14. Antiretroviral Therapy Cohort Collaboration (ART-CC), Vandenhende MA, Ingle S, May M, et al. Impact of low-level viremia on clinical and virological outcomes in treated HIV-1-infected patients. AIDS 2015; 29: 373-383.

15. Laprise C, de Pokomandy A, Baril JG, Dufresne S, Trottier H. Virologic failure following persistent low-level viremia in a cohort of HIV-positive patients: results from 12 years of observation. Clin Infect Dis 2013; 57: 1489-1496.

16. Boillat-Blanco N, Darling KE, Schoni-Affolter F, et al. Virological outcome and management of persistent low-level viraemia in HIV-1-infected patients: 11 years of the Swiss HIV Cohort Study. Antivir Ther 2015; 20: 165-175.

17. Documento de consenso de GeSIDA/Plan Nacional sobre el Sida respecto al tratamiento antirretroviral en adultos infectados por el virus de la inmunodeficiencia humana (Actualización enero 2017), 2017. Available at: http://gesida-seimc.org/wp-content/uploads/2017/ 02/gesida-guiasclinicas-2017-TAR.pdf (Accessed: 08.20. 2017).

18. Pedrol E, Viciana P, Arranz A, et al. Reasons for antiretroviral treatment change in HIV+ patients in Spain in 2010-2011. SWITCH AUDIT Study. Rev Esp Quimioter 2014; 27: 93-97.

19. de la Torre J, Santos J, Perea-Milla E, Perez I, et al. First antiretroviral therapy regimen in HIV-infected patients. Durability and factors associated with therapy changes. Enferm Infecc Microbiol Clin 2008; 26: 416-422.

20. Cohen CJ, Meyers JL, Davis KL. Association between daily antiretroviral pill burden and treatment adherence, hospitalisation risk, and other healthcare utilisation and costs in a US medicaid population with HIV. BMJ Open 2013; 3. doi: 10.1136/bmjopen-2013-003028. 